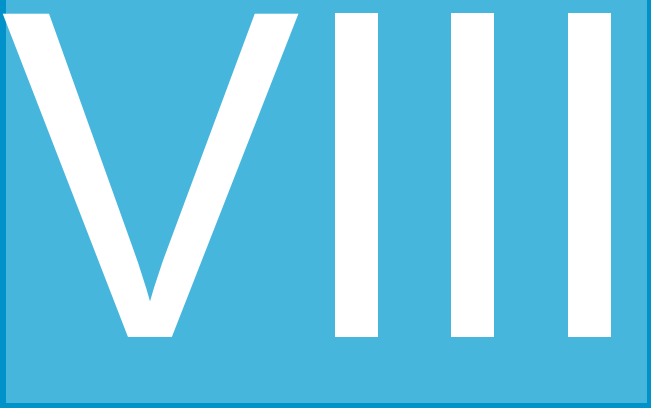

\title{
Elena de White, la Escritura, y la cuestión de la autoridad: Un vistazo histórico
}

\author{
Ellen White, the Scripture, and the issue of Authority: A Historical \\ Overview \\ Andrews University, EUA
}

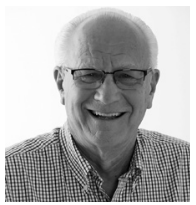

\section{George R. Knight}

El Dr. Knight es un ávido estudiante de la Biblia y la historia adventista. Ha escrito y editado más de 80 libros en diferentes áreas como historia eclesiástica, estudios bíblicos, estudios en Elena G. de White, teología, y filosofía de la educación; y muchos de ellos han sido traducidos al español, portugués, alemán, ruso, chino, etc. Algunas de sus más recientes obras son William Miller and the Rise of Adventism (2010), A. T. Jones: Point Man on Adventism's Charismatic Frontier (2012), Exploring Romans (2010), The Apocalyptic Vision and the Neutering of Adventism (2008, 2009), Exploring Thessalonians (2012), and Turn Your Eyes Upon Jesus (2013). Actualmente vive en Rogue River, Oregon (USA), donde él y su esposa Bonnie disfrutan del camping, excursionismo, canotaje y todo lo que tenga que ver con la naturaleza. 


\section{Resumen}

Los adventistas del séptimo día afirman que la Palabra de Dios contiene el "conocimiento necesario para la salvación", es la fuente de doctrina, y "es el estandarte por el cual toda enseñanza y toda experiencia deben ser probadas". No obstante, también mantienen que Elena de White tuvo un don profético válido y "autoritativo". Aquí surge una pregunta importante: los escritos de Elena de White, ¿tienen la misma autoridad que la Biblia? Con el objetivo de responder a esta pregunta desde una perspectiva histórica, el presenté artículo desarrolla el entendiendo de la autoridad de la Biblia y la autoridad de Elena de White en el adventismo del séptimo día.

Palabras clave: Elena de White, Biblia, Iglesia Adventista, autoridad.

\section{Abstract}

Seventh-day Adventists claims that the Word of God in the Bible contains the "knowledge necessary for salvation," is the source of doctrine, and "is the standard by which all teaching and experience must be tested," but also maintain that Ellen G. White had a valid and "authoritative" prophetic gift. Here arises the important question for us: do Ellen G. White's writings have the same authority than the Bible? In order to answer this question, this study will focus on showing the relationship between Ellen G. White's authority and the authority of the Bible in Adventism from a historical perspective.

Keywords: Ellen White, Holy Scriptures, Seventh-day adventists, authority. 


\section{Introducción}

La autoridad es el más básico de todos los asuntos teológicos. Las decisiones en el área de autoridad teológica moldean todas las demás áreas de una persona o comprensión de un cuerpo humano religioso. El tema de la autoridad es de interés particular en el Adventismo de Séptimo Día [IASD] porque la denominación se mantiene firme en la autoridad suprema de la Sagrada Escritura aunque también reclama a un profeta inspirado como uno de sus fundadores. La declaración actual de creencias fundamentales de la denominación, afirma que la Palabra de Dios en la Biblia contiene el "conocimiento necesario para la salvación," Es la fuente de doctrina, y "es el estandarte por el cual toda enseñanza y toda experiencia deben ser probadas," Pero también mantiene que Elena de White (1827-1915) tuvo un don profético válido y “autoritativo" (IASD, 2006).

Tales declaraciones pueden sondear (o no pueden) que todo vindica en lo abstracto, ¿pero que hace que un cuerpo humano de creyentes relacione la autoridad de un profeta moderno con la autoridad de los profetas antiguos canonizados en los 66 libros de la Biblia? Ese es el tema de este escrito. Es también un tema que les ha dado ocupación a los pensadores adventistas a través de los 165 años de la historia de su iglesia.

\section{Antecedentes de la Conexión-Cristiana}

De hecho, no es demasiado decir que el movimiento adventista del séptimo día se formó en la matriz de tensión en materia de visiones versus la Palabra. Por un lado, el Adventismo Millerita (Numbers y Butler, 1987; Knight, 1993) (uno de sus antecedentes históricos principales) el cual ha sido registrado desde junio de 1843 "no tenemos confianza de toda cualquier visión, sueños, o revelaciones privadas." Ese sentimiento estaba reafirmado en mayo de 1845 (Signs of the Times, 1843; Morning Watch, 1845) unos siete meses después del chasco Millerita relacionado con el no advenimiento de Cristo y unos cinco meses después que la joven Elena G. Harmon tuviera su primera visión (Para más detalles sobre la vida y ministerio de Elena de White vea a White, 1986 y Knight, 1996). El Adventismo Millerita fue un movimiento que basó su autoridad en un libro: la Biblia.

Uno de las otras raíces teológicas del Adventismo de Séptimo Día tuvo la misma posición sobre la autoridad de la Biblia. La Conexión Cristiana, un grupo restauracionista relacionado con el movimiento de Stone Campbell, se sujetaron a la Biblia como la única regla de fe. William Kinkade (B. 1783), quien 
fue alumno de Barton W. Stone y se convirtió en el "teólogo de este grupo" que conformaban siete hombres que fundaron La Conexión Cristiana (True Morrill, 1912; Garrett, 1981), escribió en 1829 que él en sus años anteriores se rehusó a llamarse por cualquier nombre que no sea el de "cristiano" y que él no tomaría otro libro "como estandarte sino la Biblia" (Kinkade, 1829).

Kinkade estaba ciertamente seguro sobre la autoridad suprema de la Biblia en la materia religiosa. Sin embargo, en su amplio debate sobre la "restauración del antiguo orden de cosas" afirmó que él no podría reacomodarse por "una pulgada muy pequeña" a la consigna del Nuevo Testamento. El centro del Nuevo Testamento, arguyó, son los dones espirituales, incluyendo el don de profecía, en pasajes tales como 1 Corintios 12:8-31 y Efesios 4:11-16. La presencia de dones espirituales en la iglesia es "el orden antiguo de las cosas"; todo aquel que se oponga a esto, se opone al cristianismo primitivo. Decir que Dios causó que estas dádivas cesen, es como decir que Dios ha abolido la consigna de la iglesia del Nuevo Testamento... Estos dones constituyen el antiguo "orden las de cosas". No fueron dones temporales que fueron suspendidos en la edad apostólica. Más bien, "estas dádivas, tal como están puestas en la Sagrada Escritura, componen el ministerio del evangelio" tal como se indica en el Nuevo Testamento (Kinkade, 1829).

La teología del Nuevo Testamento de Kinkade sobre la perpetuidad de los dones espirituales, en el contexto de la Biblia como la única fuente de autoridad, es importante para la comprensión del antiguo Adventismo del Séptimo Día, porque dos de los tres fundadores del movimiento habían estado en actividad con la Conexión Cristiana - José Bates como líder principal y Jaime White como un pastor Conexionista. En resumen, habían ingresado a un Adventismo desde un movimiento en el cual el teólogo más influyente (Morrill, 65) estaba sujetado a la Biblia y solo la Biblia como un determinador de fe y práctica y la continuación de dones espirituales incluyendo el de profecía en todo lo largo de la era cristiana como lo establece el Nuevo Testamento. Kinkade no pareció preocupado ante un posible conflicto entre las dos áreas de autoridad.

\section{Los primeros adventistas sobre la autoridad}

Los primeros adventistas guardadores del sábado estaban realmente claros sobre el asunto de la autoridad. Jaime White, el esposo de Elena, reveló muy exactamente la posición de la denominación en vías de desarrollo en 1847 cuando escribió que "la Biblia es una revelación perfecta y completa. Es nuestra única regla de fe y práctica." Pero incluyó en armonía con la línea de pensamiento 
de Kinkade, "Ésta no es una razón, por la que Dios no pueda mostrar el pasado, el presente y cumplimiento futuro de su palabra, en estos últimos días, por los sueños y las visiones; según el testimonio de Pedro [ver Hch 2:28; 2:17-20; Jl 2:2831]. Las verdaderas visiones son afectas a conducirnos a Dios y su Palabra escrita; pero aquellos que son dados para promover una nueva regla de fe y práctica, se separan de la Biblia, no pueden estar de Dios y deberían ser desechados" (White, J, 1847, p. 13).

En la declaración de White vemos el balance delicado seguido por varios líderes pensadores adventistas antiguos. La idea central es que la Biblia es suprema, pero que señala que Dios enviará visiones y dones espirituales durante los últimos días de la historia de la tierra para reconducir a su pueblo a la Biblia a través de los bancos de arena de la crisis del tiempo del fin. Así que el punto que White señala es el uso que Pedro hace de Joel 2:28-31 en su sermón del Pentecostés de Hechos 2 el cual no fue el cumplimiento pleno de esa profecía. Dios enviaría a Su Espíritu Santo otra vez al final del tiempo y "sus hijos e hijas profetizarían" y verían visiones antes del segundo advenimiento. White también citó 1 Tesalonicenses 5:19-21, donde Pablo dice: "No menospreciéis las profecías. Examinadlo todo y retened lo bueno" (White, J, 1847, p. 14).

Jaime White y otros líderes antiguos de la Iglesia Adventista del Séptimo Día sostuvieron sin duda que la Biblia enseña que Dios vertería el don profético durante los últimos días y que los individuos tendrían la responsabilidad de probar por los criterios de la Biblia a esos que mantienen ser profetas. Los líderes adventistas también sostuvieron sin duda que cualquier don debe ser supeditado a la Biblia en la vida de los creyentes y que cualquiera que no se subordine a ella estaría usándolo equivocadamente.

Así Jaime podría escribir en 1851 que "Todos los dones del Espíritu deberían tener sus lugares correctos. La Biblia es una roca eterna. Es nuestra regla de fe y práctica." Afirmó que si todos los cristianos fueran tan diligentes y honestos como deberían ser, podrían aprender su deber entero de la Biblia misma. "Pero," acotó Jaime:

[...] como el reverso existe y alguna vez ha existido, Dios en su mucha misericordia ha compadecido la debilidad de su pueblo y ha incrustado los dones en la iglesia del evangelio para corregir sus errores y conducirlos a su Palabra Viviente. Pablo dice que son para el "perfeccionamiento de los santos, hasta que todos nosotros lleguemos a la unidad de la fe" Efe. $4: 12,13$.- La necesidad extrema de la iglesia en su estado imperfecto es la oportunidad de Dios para manifestar los dones del Espíritu. 
Cada cristiano está por consiguiente en el deber de tomar la Biblia como una regla perfecta de fe y deber. Debería orar fervientemente para ser auxiliado por el Espíritu Santo en la búsqueda de toda la verdad en las Sagradas Escrituras para su entera consagración. No está en libertad de apartarse de ella para aprender su deber a través de cualquiera de los dones. Decimos que el momento preciso cuando coloca los dones en un lugar equivocado toma una posición sumamente peligrosa. La Palabra debería ir delante, y el ojo de la iglesia debería ser colocado sobre ella, como la regla para caminar sobre la fuente de sabiduría y de la cual aprender "toda buena obra." Pero si una porción de la iglesia yerra de las verdades de la Biblia y se vuelve débil, enfermiza y la grey se dispersa, entonces parece necesario para Dios utilizar los dones del Espíritu para corregir, reanimar y sanar lo falible, le deberíamos dejar trabajar (White, J, 1851).

En una manera similar en 1868 Jaime White les advirtió a los creyentes

[...] deje a los dones tener su lugar correcto en la iglesia. Dios nunca los ha incrustado al frente y nos ha ordenado a nosotros que miremos hacia ellos para guiarnos en el camino de la verdad y el sendero al Cielo. Él ha magnificado su palabra. Las Sagradas Escrituras del Antiguo y Nuevo Testamento son la lámpara que ilumina el camino del hombre hacia el reino. Siga eso. Pero si usted yerra de la verdad bíblica y está corriendo peligro de perderse, puede ser que la voluntad de Dios en el tiempo de su elección correcta [a través de los dones] le lleve de vuelta a la Biblia (White, J, 1868).

A estas alturas es importante reconocer que solo porque los antiguos líderes adventistas creyeron que el espíritu de profecía de Elena de White fue supeditado a la autoridad de la Biblia, no quiere decir que creyesen que su inspiración sea de una calidad inferior que la de los escritores de la Biblia. Por el contrario, creyeron que la misma Voz de autoridad que habló a través de los profetas de la Biblia también se comunicó a través de ella.

Encontramos un balance cuidadoso aquí. Si bien los adventistas antiguos miraron su inspiración como de igual procedencia divina que el de los escritores de la Biblia, no la vieron con la misma autoridad. Elena de White y sus compañeros adventistas opinaron que su autoridad derivaba de la Biblia y así no podría ser igual a ella.

Como consecuencia, su autoridad fue no trascender o contradecir los linderos establecidos en la verdad bíblica. Como Elena de White tan apropiadamente escribió en 1871, "Los Testimonios escritos no son para dar nueva luz, sino para imprimir vívidamente en el corazón las verdades de la inspiración ya reveladas" en la Biblia (White, E, 1996, p. 535). 
La comprensión de Elena acerca del don armonizó bien con el de su marido. Así en 1851 ella podría escribir en la conclusión de su primer pequeño libro:

Recomiendo al amable lector la Palabra de Dios como regla de fe y práctica. Por esa Palabra hemos de ser juzgados. En ella Dios ha prometido dar visiones en los "postreros días"; no para tener una nueva norma de fe, sino para consolar a su pueblo, y para corregir a los que se apartan de la verdad bíblica (White, E, 1851, p. 64).

Es importante reconocer que Elena de White creyó que sus visiones le fueron otorgadas para ser una guía de la comunidad Adventista en vez de la Iglesia Cristiana en general. Escribiéndoles a los creyentes adventistas en 1871, ella indicó:

Si usted hubiese hecho de la palabra de Dios su estudio, con un deseo para alcanzar el estandarte de la Biblia [..., ] no habría necesitado los Testimonios [es decir, su consejo]. Es porque usted se ha descuidado de informarse sobre el Libro inspirado de Dios que él ha buscado alcanzarlos por testimonios simples, directos, llamando su atención a las palabras de inspiración que se había descuidado de obedecer y urgiéndole a modelar sus vidas en conformidad con sus enseñanzas puras y elevadas (White, E, 1996, 535).

Las declaraciones teóricas sobre la relación de la autoridad de la Biblia y de Elena de White fueron muy coherentes. Pero, necesitamos preguntarnos, ¿practicaron los adventistas antiguos lo que predicaron sobre el tema? Más específicamente, ¿las visiones de White tuvieron un papel significativo en la formación doctrinal? y ¿Cómo sus escritos se relacionan con la interpretación de la Biblia?

Fácilmente el segundo punto es el más tratado, desde las primeras décadas del Adventismo los escritos de Elena de White no fueron pensamientos de interpretación al significado de pasajes bíblicos. En lo que se refiere a la formación doctrinal, Jaime White escribió en 1855:

Debería ser comprendido que todos estos puntos de vista mantenidas por el cuerpo de Guardianes del Sábado, fueron extraídos de las Sagradas Escrituras antes de que la señora W. tuviese cualquier visión con relación a ellas. Estas aseveraciones están fundadas en las Sagradas Escrituras como su única base (White, J, 1855) 
Esa declaración se encuentra en el contexto de un debate sobre las doctrinas adventistas del séptimo día siendo "producto de las visiones" en vez "de la Biblia". Esa fue una acusación popular entre los detractores de la denominación. Miles Grant, por ejemplo, arguyó en 1874 en The world crisis (una de la principales publicaciones de Advent Christian) que la comprensión sobre el santuario celestial que tuvieron los guardadores del sábado había sido extraída a través de visiones de Elena de White (Grant, 1874)

Urías Smith vigorosamente respondió a esa acusación. "Centenares de artículos," dijo:

han sido escritos sobre ese tema [del santuario]. Pero ninguno de ellos es resultado de visiones de cualquier autoridad sobre el mismo, o la fuente de donde la hemos mantenido ha sido derivada de cualquier visión. Ni cualquier predicador alguna vez se refiere a ellos sobre esta pregunta. La proclamación es invariablemente de la Biblia, donde hay abundantes evidencias para las aseveraciones que mantenemos sobre este tema (Smith, 1874).

Por supuesto, una cosa es hacer tales declaraciones como las citadas por Smith y Jaime White y absolutamente otra es substanciarlas. Lo que llama la atención acerca de la aseveración de Smith es que cualquier persona que estando dispuesta a regresar a la antigua literatura adventista del séptimo día puede verificarla o desmentirla. En materia del santuario celestial Paul Gordon ha verificado las declaraciones de Smith en El Santuario, 1844 y los Pioneros (Gordon, 1983). En una escala más amplia y extensa una investigación realizada por Burt (2002), Pöhler (2000), y Knight (2000) han demostrado que las diversas doctrinas del Adventismo fueron originadas e incorporadas por varios individuos, de los cuales ninguno se convirtió en adventista del séptimo día. La contribución adventista había integrado diversas doctrinas que habían aceptado de la Biblia y estaban basadas en estudios teológicos apocalípticos. Pero incluso esa fue una contribución hecha por José Bates en vez de Elena de White (Knight, 2004). Sus primeras visiones tendieron a ser visiones de confirmación del estudio de la Biblia o trataron de construir unidad en materia de detalles.

Los antiguos adventistas del séptimo día parecen haber sido el pueblo del "Libro." Parecen haber sido coherentes en la teoría y práctica en su observancia de la Biblia como la única fuente de autoridad doctrinal y su aceptación de un profeta moderno. Pero eso cambiaría. 


\section{La era de 1888 y la autoridad}

La transformación del Adventismo con respecto a la utilización de los escritos de Elena de White en relación a la Biblia no puede ser definida claramente con exactitud completa. Pudo haber comenzado a finales de 1870 pero es abiertamente evidente para 1880 . Eso fue particularmente cierto ya que la denominación se acercaba al congreso de la Asociación General de 1888. Ese congreso sería uno de los más significativos en la historia adventista. Estuvo en juego la comprensión del evangelio y la ley y cómo deberían relacionarse. Los temas subsiguientes fueron la definición de la ley en Gálatas y los diez cuernos de Daniel 7 (Olson, 1981; Knight, 1998).

En la lucha sobre los diversos temas la pregunta sobre autoridad religiosa se trató de manera importante. Desviándose de la anterior posición adventista sobre la primacía absoluta de la Sagrada Escritura, la segunda generación de líderes de la denominación buscó solucionar sus asuntos teológicos y bíblicos a través del uso de la autoridad humana en relación con la opinión experta, la posición autoritativa, la tradición adventista y la mayoría de votos (Knight, 1989). El elemento reformatorio que luchaba por una teología más centrada en Cristo desechó todas las apelaciones confiadas a la autoridad humana con el fin de solucionar asuntos teológicos y bíblicos. Elena de White, quien era la única que vivía de los antiguos fundadores de la denominación apoyaba firmemente a los reformadores en su posición de dar total primacía a la Sagrada Escritura.

Pero el liderazgo oficial de la denominación no sólo trató de usar la autoridad humana para apuntalar lo que vieron como una amenaza para la teología adventista tradicional, sino que eso también incluía la autoridad de Elena de White. En los ojos del presidente de la Asociación General George I. Butler una palabra autoritativa de la pluma de Elena de White solucionaría los asuntos bíblicos y teológicos ante la iglesia.

Butler y sus colegas tomaron dos declaraciones de los escritos de Elena de White para resolver tales problemas. Primero ella debía proveer una declaración escrita sobre los temas controversiales relacionados con la interpretación de Gálatas y Daniel. Entre junio de 1886 y octubre de 1888 el batallador presidente escribió a Elena de White una serie de más de una docena de cartas pidiendo y a veces exigiendo, que ella hiciera uso de su autoridad para decisión de asuntos controversiales (Knight, 1989, p. 104-107).

Significativamente, Elena de White se rehusó a dejar que Butler y sus colegas usaran sus escritos para decidir sobre los asuntos bíblicos y teológicos y así causar división a la denominación. Ella inclusive llegó a decirles a los delegados del 
congreso de la Asociación General de 1888 el 24 de octubre, que fue providencial que ella perdiera el único escrito en la cual ella supuestamente había identificado la ley en Gálatas. "Dios mío," ella afirmó, "hay un propósito en esto." Él quiere que nosotros vayamos a la Biblia y tengamos la prueba de la Sagrada Escritura" (White, E, 1888) En otras palabras, ella desechó la posición de Butler y otros que trataron de buscar en sus escritos un comentario inspirado de la Biblia.

La segunda estrategia de la coalición del Butler en la era de 1888 fue usar los escritos publicados de Elena de White para establecer la interpretación "correcta" a los asuntos controversiales. Con relación a la interpretación de la ley en Gálatas, por ejemplo, citó de sus Bosquejos de la Vida de Pablo (1883) para lograr la comprensión correcta. De nuevo, ella desechó su maniobra, afirmando: "No puedo tomar una posición hacia ningún bando hasta que haya estudiado la pregunta" (Knight, 1989, p. 107,108) Ella no estaba dispuesta a dejar utilizar sus escritos para decidir asuntos interpretativos. Pues la Sagrada Escritura era suprema. Mientras sus escritos podrían utilizarse para aplicar principios bíblicos a su contexto, no debieron ser usados autoritariamente para darle el punto final sobre un estudio de la Sagrada Escritura. Y para asegurarse que no serían usados inapropiadamente para solucionar ese asunto en particular ella quitó las citas sobre la ley en Gálatas cuándo revisó el libro unos años más tarde (Parson, 1919, p. 20).

Nadie defendió el principio de la primacía de la Sagrada Escritura más vigorosamente y más a menudo durante la era de 1888 de la historia adventista que Elena de White. "Queremos una evidencia bíblica para cada punto en el que avanzamos," le escribió Butler en abril de 1887. En julio de 1888 ella publicó en la principal publicadora adventista que "la Biblia es la única regla de fe y doctrina." Y en agosto ella les escribió a todos los delegados del cercano congreso de la Asociación General que:

la Palabra de Dios es el gran detector de error; Por ello creemos que todo debe ser sujeto a ella. La Biblia debe ser nuestro estandarte para cada doctrina y cada práctica [...] No debemos recibir la opinión de nadie sin compararla con la Sagrada Escritura. Aquí está la autoridad divina que es la suprema en materias de fe. Es la Palabra del Dios vivo la que debe decidir todas las controversias (White, E, 1887)

La lucha sobre la autoridad en las reuniones de 1888 aparentemente dejó huellas en el ministerio de la denominación. El hijo de Elena, W. C. White, escribió al final del Congreso que "muchos van hacia adelante de esta reunión determinados a estudiar la Biblia como nunca antes" (White, W, 1888). 
Las lecciones sobre autoridad religiosa que se relacionaron con el congreso de la Asociación General de 1888 fueron cruciales para evaluar la autoridad de la Biblia en relación a la autoridad profética en el Adventismo del Séptimo Día. La misma Elena de White se había afianzado a la posición del antiguo Adventismo. Pero muchos de los líderes y ministros de la segunda generación se habían movido de esa posición bien definida y habían tratado de usar la autoridad profética de Elena de White para decidir asuntos teológicos y exegéticos.

\section{A.T. Jones inicia la etapa de problemas con la autoridad en el siglo XX}

Uno de los infortunados desarrollos en el Adventismo en relación con la autoridad fue que también muchos de los adventistas en el siglo XX tomarían la posición desechada por los fundadores de la denominación y Elena de White. El líder en tal movimiento, por extraño que parezca, fue Alonzo T. Jones, uno de los compañeros reformadores de Elena de White durante la era de 1888 . En su vasta lectura semanal de oración de 1894 titulada "Los Dones: Su presencia y objeto" Jones señaló que el Espíritu Santo es el único intérprete de la Biblia y que "la interpretación del Espíritu es infalible." De tal proposición se movió al papel de los testimonios de Elena de White, usando correctamente declaraciones de que el propósito de sus escritos no fue proveer información nueva, sino para conducir a sus lectores a la Biblia misma (Jones, 1894).

Hasta ese punto su discusión pareció lo suficientemente bien fundada, pero entonces se salió del curso en una línea de pensamiento que contradijo los principios y la posición biblica histórica del Adventismo sobre la relación entre el don de Elena de White y la Biblia. Jones escribió:

El uso correcto de los Testimonios, por consiguiente, no es utilizarlos tal como están en ellos mismos, como si estuviesen aparte de la Palabra de Dios en la Biblia; sino para estudiar la Biblia a través de ellos, a fin de que con las cosas expuestas en ellos podamos ver y conocer que están en la Biblia; así que no presenta cosas de otros Testimonios en sí mismos, sino de la Biblia misma [...] Este y solo este es el uso correcto de los Testimonios, ya sean usados en privado o en público [...] Esto nos hará poderosos en la Sagrada Escritura" (Jones, 1894).

El argumento de Jones, pretendía sostener la primacía de la Biblia, subordinándola a los escritos de Elena de White. Así que, para Jones y los que compartieron su lógica, sus escritos llegaron a ser mirados como comentarios 
divinos e infalibles de la Biblia. Esa, por supuesto, fue la misma posición que Elena de White había desechado de las luchas teológicas en las reuniones de alrededor de 1888.

El uso de los escritos de White como comentario divino e infalible, un enfoque que le dio a ella el punto final sobre el estudio de la Sagrada Escritura, fue uno de los varios problemas relacionados con la autoridad que el influyente Jones alegó al Adventismo del siglo XX (Knight, 1987). En 50 años la posición de muchos adventistas en relación a la autoridad de Elena de White y la Biblia había sido completamente transformada de la posición de los fundadores de la denominación.

\section{Los adventistas y la autoridad religiosa en el siglo XX}

El enfoque de Alonzo T. Jones sobre la autoridad de Elena de White en relación a la autoridad de la Biblia tomó posición firme de grandes sectores del Adventismo en los tempranos días del siglo $X X$, incluso hubo voces influyentes que alegaron razones contra él. La mayor lucha en el nuevo siglo sobre el asunto de la autoridad fue estimulada por una controversia sobre la identidad del "continuo" de Daniel 8. En esa lucha, aquellos que apoyaron la antigua interpretación sostuvieron que lo nuevo subvertiría la teología de la denominación porque una declaración en los Primeros Escritos de Elena de White se aferró a la interpretación adventista tradicional. El líder de aquellos que apoyaban la antigua interpretación sostuvo la opinión que hacer cualquier cambio en la posición establecida subvertiría la autoridad de White. Fue realmente explícito en su punto de vista sobre la relación de sus escritos con la Biblia.

Debemos comprender tales expresiones para asistir al Espíritu de Profecía [es decir, los escritos de Elena de White] [. . . . Con este propósito el Espíritu de Profecía llega a nosotros [. . . ] Todos los puntos deben ser solucionados" de esa manera (Haskell, 1907).

Elena de White estaba en desacuerdo con la discusión. Ella no pidió que sus escritos se usaran para decidir el asunto.

Le ruego a los hermanos Haskell, Loughborough, Smith, y otros de nuestros hermanos líderes, que no hagan referencia a mis escritos para sostener sus puntos de vista sobre "el continuo" [...] No puedo consentir que cualquiera de mis escritos sea tomado como base para esta materia (White, E, 1910). 
Así que ante las luchas sobre el continuo y la ley en Gálatas, Elena de White tomó la posición de que sus comentarios no fuesen usados como si ella fuera un comentarista infalible para decidir el significado de la Biblia.

W. C. White también nos provee de una comprensión profunda interesante en el asunto de la relación de su madre a la Biblia. "Algunos de nuestros hermanos," escribió:

[...] están demasiado sorprendidos y decepcionados porque mi Madre no escribió algo decidido sobre la pregunta referente a lo que es "el continuo" y así trajo un final al desacuerdo presente. A veces he esperado esto, pero como he visto que Dios no ha escogido arreglar el asunto por una revelación a través de Su mensajera, he llegado cada vez más a creer que fue la voluntad de Dios que un estudio cabal debería estar hecho de la Biblia y la historia, hasta que una comprensión evidente de la verdad fuere ganada (White, W, 1910).

Su negativa a funcionar como un comentarista infalible de la Biblia no debería haber asombrado a alguien. Ella no había asumido ese papel en el pasado, sino siempre apuntó a las personas la necesidad de estudiar la Biblia por ellos mismos. Ella nunca tomó la posición de "usted debe dejarme decirle lo que quiere decir la Biblia realmente."

A pesar de la claridad de Elena White sobre el tema en batalla: la identidad del continuo rugió durante más de dos décadas. El tema del diario en sí mismo no fue tan crucial. La cuestión verdadera fue la autoridad de Elena de White como una comentarista divina de la Sagrada Escritura. Tales títulos como ¿Tenemos un Infalible "Espíritu de Profecía"? Refleja los sentimientos de esos que estaban tan preocupados con el tema que en 1922 utilizaron el asunto de autoridad de Elena de White para derrocar a Arturo G. Daniells, quien había sido presidente de la Asociación General de los Adventistas del Séptimo Día desde 1901 (Holmes, 1920; Murray, 1982).

El papel autoritativo de Elena de White no fue solo una preocupación con los disidentes denominacionales. Los líderes en el centro de la iglesia también lo propugnaron. Así F. M. Wilcox, editor influyente de la revista denominacional Review and Herald, podrían reclamar en 1921 que sus escritos "constituyen un comentario espiritual sobre la Sagrada Escritura. Y en 1946 Wilcox afirmó antes del congreso de la Asociación General que los escritos de Elena de White estaban "muy por encima de todos los otros comentarios" porque fueron "comentarios inspirados, motivados por la influencia del Espíritu Santo [...] El que fracasa en hacer esta distinción deja saber que tiene fe si acaso un poquito en la doctrina de dones espirituales en su aplicación para la iglesia hoy (Wilcox, 1921). 
Para mediados de siglo la posición de Wilcox había llegado a ser por lejos la posición dominante en la iglesia. Tanto fue así que el extensivo comentario bíblico adventista (1953-1957) tuvo una sección inédita de comentarios de Elena de White al final de cada volumen y una lista de referencias para sus usos de diversos textos publicados después del debate de cada capítulo bíblico. Esa misma disposición condujo a las personas a ver sus escritos más que nunca como un comentario inspirado en la Biblia.

La denominación en términos generales no había aprendido mucho de su historia. Ni aprendió las lecciones de Elena de White al negarse al permitir que sus escritos fuesen usados en el comentario, en cada lucha como la ley en Gálatas y la identidad del continuo.

Hasta su muerte en 1915 sondeó el mismo mensaje sobre la relación de sus escritos con la Biblia que junto a y su esposo tuvieron al principio del movimiento adventista. En 1903, por ejemplo, ella escribió: “la mínima atención es dada a la Biblia, y el Señor le ha dado una luz menor para conducir a los hombres y las mujeres a la mayor" (White, E, 1903). A través de su ministerio ella aseguró que la función principal de sus escritos fue conducir a las personas a la Biblia.

En lo que se refiere a la autoridad de la Biblia, ella continuó sujetando la posición que los pioneros adventistas habían recibido en herencia de la tradición William Kinkade. "En Su palabra," ella dijo en 1911,

Dios ha cometido para los hombres el conocimiento necesario para la salvación. Las Sagradas Escrituras deben ser aceptadas como una revelación autoritativa e infalible de Su voluntad. Son el estandarte del carácter, el divulgador de doctrinas, y la prueba de experiencia [.. . El El Espíritu no fue otorgado ni alguna vez puede ser otorgado para reemplazar la Biblia; Pues las Escritura explícitamente manifiestan que la Palabra de Dios es el estandarte por el cual toda enseñanza y toda experiencia deben ser probadas.

Ella continuó, como Kinkade y los líderes adventistas antiguos, indicando que, "después del cierre del canon de la Sagrada Escritura" el Espíritu Santo todavía continuó su trabajo apropiado, incluyendo el espíritu de profecía, y haría eso hasta el segundo advenimiento (White, E, 1950).

Otros pudieron haber ido a la deriva de la posición del antiguo Adventismo sobre la autoridad de Elena de White en relación a la Biblia, pero ella parece haberse mantenido en su rumbo. Y ella no fue la única. La conferencia biblica de administradores y profesores de religión de la denominación en 1919 es notable por su franqueza sobre el tema. C. L. Benson, por ejemplo, apuntó de manera desaprobatoria que muchos adventistas pongan más énfasis en los escritos de Elena de White que en la Biblia (Bible Conference Minutes, 1919). Y 
Arturo G. Daniells, el presidente de la denominación, estuvo mucho más cerca con Jaime y Elena White y los otros pioneros de Adventismo de Séptimo Día ya que fue contemporáneos con algunos de ellos cuando comentó "debemos obtener nuestra interpretación de este Libro [La Biblia], primordialmente. Pienso que se explica a sí mismo, y pienso que podemos comprenderlo, fundamental y directamente, sin recurrir a los Testimonios para probar esta." W. E. Howell, director de educación de la Asociación General, dijo "el espíritu de profecía dice que la Biblia es su exponente." Y para ese comentario Daniells respondió: "Sí, pero he oído que los ministros dicen que el espíritu de profecía es el intérprete de la Biblia. Oí que fue predicado en el Congreso de la Asociación General algunos años atrás [por $\mathrm{A}$. T. Jones], que la única manera en que pudiésemos entender la Biblia era a través de los escritos del espíritu de profecía." J. M. Anderson sumó que "él también dijo 'intérprete infalible.." Daniells respondió observando que esa "no es nuestra posición, y no es correcto que el espíritu de profecía sea el único intérprete seguro de la Biblia. Esa es una doctrina falsa, una aseveración falsa. No se mantendrá en pie."

Daniells procedió correctamente igual que los pioneros adventistas "obtuvieron su conocimiento de las Sagradas Escrituras tomando el camino de través de ellos mismos. Me angustia oír la manera de hablar de algunas personas, que el espíritu de profecía les condujo y le dio toda la instrucción, todas las doctrinas, de los pioneros [...]. Eso no está de acuerdo con los mismos escritos... Somos informados cómo [...] Buscaron las Sagradas Escrituras juntos y estudiaron y oraron hasta que llegaron a estar unidos." Él entonces expresó su súbita desilusión hacia estos adventistas "quienes buscan alrededor para encontrar una declaración en los Testimonios y no le dedican tiempo al estudio profundo de la Biblia" (Bible Conference Minutes, 1919).

Daniells y sus colegas en 1919 pudieron haber tenido una posición correcta sobre la relación de los escritos de Elena de White y la Biblia, pero su oportunidad del momento no pudo haber sido más desastrosa. En los años de 1920 verían la crisis fundamentalista sobre la autoridad bíblica alcanzar un clímax explosivo y el Adventismo sería extraído en el vórtice de una lucha que conllevaría no sólo los asuntos bíblicos sino también lo relacionado a la autoridad de Elena de White. Esos que hablaron abiertamente en la conferencia biblica de 1919, incluyendo al líder de la denominación, perderían sus trabajos. Entretanto, a minutas de esta reunión abierta estaban resueltamente guardados "en una bóveda" donde se perdieron por seis décadas. La conferencia pasó al olvido junto con la posición sobre la autoridad arraigada por Elena de White y los fundadores del Adventismo del Séptimo Día (Mansell, 1975). 
A mediados de la década del siglo XX se encontraron adventistas que usaban cada vez más los escritos de Elena de White para fundamentar asuntos bíblicos y teológicos. Pocos abiertamente habrían admitido que ponían la autoridad de White por encima de la Biblia, pero sus escritos y debates señalaron que excesivamente muchos adventistas (si no más) gastaban más tiempo con Elena de White que con la Biblia. Ella ha sido para muchos la palabra final sobre cualquier pasaje bíblico y ha sido utilizada como autoridad doctrinal. Una palabra de ella tendía a terminar cualquier debate. La posición oficial de la denominación puede no haber cambiado pero la práctica sí. En 1960 las nuevas prácticas se habían vuelto firmemente arraigadas y fundamentadas ante la mayoría de adventistas pensaron que, esa era la manera como su iglesia siempre ha utilizado la autoridad de White.

\section{Hacia una perspectiva más saludable}

Esos días de inocencia histórica comenzaron a desmoronarse en 1970 cuando Spectrum (una publicación adventista independiente de la iglesia) y una nueva generación de eruditos educados académicamente en historia y biblia comenzaron a publicar artículos sobre Elena de White exigiendo una reexaminación crítica de sus escritos. En la siguiente década y media fue rigurosamente examinado casi cada aspecto de su trabajo, incluyendo su rol en la formación doctrinal del antiguo Adventismo y la relación entre la autoridad de sus escritos con la Biblia. Entre los tempranos años de 1980 y los subsiguientes años de 1990 el patrón histórico de esa relación tan esbozado más temprano en este escrito estaba convirtiéndose en el más conocido entre sectores significativos del liderazgo, clero y laicado de la denominación.

Significativamente, en 1981 Robert Olson, director del Patrimonio Elena de White, encaró los problemas inherentes acerca de infalibilidad del comentario cuando escribió que:

dar un control interpretativo completo e individual sobre la Biblia, en efecto, elevaría a esa persona por encima de la Biblia. Incluso sería un error dejar aun al apóstol Pablo ejercitar control interpretativo sobre todos los otros escritores de la Biblia. En tal caso, sería Pablo y no toda la Biblia, la única autoridad final (Olson, 1981, p. 41)

Olson (1981) indica que "los escritos de Elena de White son generalmente de naturaleza homilética o evangelistica y no estrictamente exegéticos." De hecho, 
ella a menudo acomodó las palabras de un texto a sus propias necesidades homiléticas. Así ella podría derivar significados completamente diferentes sobre el mismo pasaje a merced de su propósito. Olson hace notar correctamente que ella algunas veces interpretaba el texto exegéticamente, sin embargo ella "generalmente" habló desde el punto de vista homilético (Olson, 1981). Pero ese hecho no significa que ella alguna vez mantuviese ser una comentadora divina de la Sagrada Escritura.

En los inicios del siglo XXI la corriente principal del Adventismo tiene una comprensión más saludable de la relación entre la autoridad de Elena de White y la Biblia. Sus teólogos y comentadores bíblicos tienen una mejor comprensión de la posición bíblica que los fundadores de la iglesia, incluyendo a la misma Elena de White. Es decir que prácticamente ella no es un determinador de la doctrina o la última palabra sobre el estudio de la Sagrada Escritura. Pero los viejos hábitos y las formas de pensar son difíciles de morir para algunos, aun cuando conocen los hechos. Y hay muchos en la corriente principal de los adventistas que aún no han alcanzado a conocer los hechos. Pero al fin y al cabo la corriente principal del Adventismo está a años luces de donde estaba en 1980 acerca de su comprensión de la autoridad de Elena de White.

No se puede decir lo mismo del Adventismo sectario. Los perfeccionistas y sub-denominaciones fundamentalistas dentro de la denominación todavía confían cuantiosamente en Elena de White por su teología y no tienen problemas mirándola como un comentarista infalible sobre la Biblia. Este sector del Adventismo incluso ha desarrollado una Biblia de estudio de Elena de White que tiene notas de sus escritos y referencias en los márgenes. Tal Biblia habría sido completamente rechazada en la era temprana del Adventismo. Si bien esa Biblia de Estudio es publicada por un grupo independiente es infortunadamente comercializada por su principal publicadora. Hace unos años atrás persuadí a la gerencia de la casa editorial a descartar su mercadeo de la Biblia de Estudio de Elena de White, porque ella la desaprobaría vigorosamente por lo que sabemos históricamente sobre sus principios. Pero después de algunos meses el presidente de la casa editorial me llamó por teléfono para notificarme que decidían reversarme porque hubo una buena demanda de la Biblia de Estudio y se vendía bien. ¡Eso en cuanto a los principios más altos!

Los grupos adventistas sectarios son críticos de la corriente principal del Adventismo por su "traición" a la profeta y a menudo se consideran a sí mismos en una forma u otra los verdaderos adventistas históricos. Infortunadamente, su comprensión de los focos de la historia sobre el período de 1920 a 1950 y el enfoque de los escritos de Elena de White que inician con A. T. Jones de 1890 
en adelante, han fracasado en captar la comprensión bíblica de los fundadores de la denominación, incluyendo a la misma White.

Mencioné al principio de mi estudio que la pregunta de autoridad religiosa especialmente le interesa a un movimiento cristiano que cree en la autoridad de Sagrada Escritura pero también reclama haber tenido a un profeta inspirado como uno de sus fundadores. Ciertamente ha sido así en el adventismo del pasado y tal parece ser que continuará siéndolo para el futuro. En conjunto, el Adventismo desde 1880 ha hecho las cosas mejor relacionándolos en la teoría y en la práctica. Pero los fundadores, incluyendo a Elena de White, lograron ser coherentes en la teoría y práctica. Esos adventistas que comprenden su historia sobre el tema están en una posición privilegiada por armonizar con ellos hoy. Pero esos que permanecen inocentes de esa historia más probablemente continuarán el acercamiento problemático de mediados del siglo XX, entre tanto pregonémosles que eso debe ser vindicado. 


\section{La relación entre la autoridad de Elena de White}

\section{Referencias}

Bible Conference Minutes. (1919). The Use of the Spirit of Prophecy in Our Teaching of Bible and History. 30 de julio, 39.

Burt, M. (2002). The Historical Background, Interconnected Development, and Integration of the Doctrines of the Sanctuary, the Sabbath, and Ellen G. White's Role in Sabbatarian Adventism from 1844 to 1849. Disertación doctoral, Andrews University.

Garrett, L. (1981). The Stone-Campbell Movement: An Anecdotal History of Three Churches Joplin, MO: College Press.

Gordon, P. (1983). The Sanctuary, 1844, and the Pioneers. Washington, DC: Review and Herald.

Grant, M. (1874). World's Crisis, 25 de noviembre.

Haskell, S. (1907). Carta, 15 de noviembre a W. W. Prescott.

Holmes, C. (1920). Have We an Infallible "Spirit of Prophecy"? n.p.: por el autor.

Iglesia Adventista del Séptimo día (2006). Creencias de los Adventistas del Séptimo Día: Una exposición de las doctrinas fundamentales de la Iglesia Adventista del Séptimo Día. Nampa, ID: Pacific Press Publishing Association.

Jones, A. (1894). The Gifts: Their Presence and Object, Home Missionary Extra, diciembre.

Kinkade, W. (1829). The Bible Doctrine of God, Jesus Christ, the Holy Spirit, Atonement, Faith, and Election; to Which Is Prefixed Some Thoughts on Natural Theology and the Truth of Revelation. New York: H. R. Piercy.

Knight, G. (1987). From 1888 to Apostasy: The Case of A. T. Jones. Washington, DC: Review and Herald.

Knight, G. (1989). Angry Saints: Tensions and Possibilities in the Adventist Struggle over Righteousness by Faith. Washington, DC: Review and Herald.

Knight, G. (1993). Millennial Fever and the End of the World: A Study of Millerite Adventism Boise, ID: Pacific Press.

Knight, G. (1996). Meeting Ellen White: A Fresh Look at Her Life, Writings, and Major Themes Hagerstown, MD: Review and Herald.

Knight, G. (1998). A User-Friendly Guide to the 1888 Message. Hagerstown, MD: Review and Herald.

Knight, G. (2000). A Search for Identity: The Development of Seventh-day Adventist Beliefs. Hagerstown, MD: Review and Herald.

Knight, G. (2004). Joseph Bates: The Real Founder of Seventh-day Adventism. Hagerstown, MD: Review and Herald.

Mansell, D. (1975). How the 1919 Bible Conference Transcript Was Found. Manuscrito inédito, 6 de julio.

Morning Watch (1845). Conference of Adventists at New York. 15 de mayo.

Murray Valentine, G. (1982). William Warren Prescott: Seventh-day Adventist Educator. Disertación doctoral, Andrews University.

Numbers, R., Butler, J. eds. (1987). The Disappointed: Millerism and Millenarianism in the Nineteenth Century. Bloomington: Indiana University Press.

Olson, A. (1981). Thirteen Crisis Years: 1888-1901. Washington, DC: Review and Herald.

Olson, R. (1981). One Hundred and One Questions on the Sanctuary and on Ellen White. Washington, DC: Ellen G. White Estate.

Parsons, D. (1919). Inspiration of the Spirit of Prophecy as Related to the Inspiration of the Bible. Bible Conference Minutes, 1 de agosto. 
George R. Knight

Pöhler, R. (2000). Continuity and Change in Adventist Teaching: A Case Study in Doctrinal Development. Frankfurt Am Main: Peter Lang.

Signs of the Times (1843). Declaration of Principles. 7 de junio.

Smith, U. (1874). The Sanctuary. RH, 22 de diciembre.

True Morrill, M. (1912). A History of the Christian Denomination in America: 1794-1911 A. D. Dayton, $\mathrm{OH}$ : Christian Publishing.

White E. (1887). Carta, 5 de abril a G. I. Butler y Urías Smith.

White, A. (1986). Ellen White, 6 vols. Washington, DC: Review and Herald.

White, E. (1851). A Sketch of the Christian Experience and Views of Ellen G. White. Saratoga Springs, NY: Jaime White.

White, E. (1888). Morning Talk by Ellen G. White. Manuscrito 9. Silver Spring, MD: Ellen G. White Estate, 24 de octubre.

White, E. (1910). Our Attitude Toward Doctrinal Controversy. Manuscrito 11. Silver Spring, MD: Ellen G. White Estate, 31 de julio.

White, E. (1950). The Great Controversy between Christ and Satan, 1911 ed. Mountain View, CA: Pacific Press.

White, E. (1996). Testimonios para la iglesia. Miami, FL: Asociación Publicadora Interamericana.

White, J. (1847). A Word to the "Little Flock" (n. p.: Jaime White).

White, J. (1851). The Gifts of the Gospel Church. Review and Herald (RH), 21 de abril.

White, J. (1855). A Test. RH, 16 de octubre.

White, J. (1868). Time to Commence the Sabbath. RH, 25 de febrero.

White, W. (1888). Carta, 2 de noviembre a Smith Sharp.

White, W. (1903). An Open Letter. RH, 20 de enero.

White, W. (1910). Carta, 31 de julio a P. T. Magan.

Wilcox, F. (1921). The Study of the Bible, Aided by the Writings of the Spirit of Prophecy. RH, 3 de febrero. 